\title{
How does Online Formative Feedback Impact Student's Motivation and Self-Directed Learning Skills during the COVID-19 Pandemic?
}

\author{
Le Thai Hung \\ VNU - University of Education, \\ 144 Xuan Thuy, Cau Giay, \\ Hanoi, Vietnam
}

DOI: https://doi.org/10.36941/jesr-2021-0101

\section{Abstract}

This research aims to prove the influences of online formative feedback on students' motivation and selfdirected learning skills in the time of COVID-19. The questionnaire was sent to 645 students who have completed at least seven blended learning courses. They were asked to choose one class to describe the frequencies of assessment activities and their characteristics. The data was analyzed using SPSS and PLS software, showing that online feedback significantly positively impacts student motivation and self-directed learning skills, except for self-assessment. Therefore applying technology in assessment can be a good solution during the pandemic time. The research also implies that the effectiveness of online feedback depends on the way it performs. Thus, the faculties should develop strategies to confirm the assessment's validity and efficiency.

Keywords: Online formative feedback, motivation, self-directed learning skills

\section{Introduction}

Giving feedback is an essential part of the assessment. While summative assessment aims to provide judgment at the end of learning periods by scoring the test, formative assessment helps students know where they are and how to get their goal during the learning process (Garrison \& Ehringhaus, 2007). Anyone, such as teachers, classmates, parents, and maybe by their books or experience, can give students valuable feedback (Hattie \& Timperley, 2007). Providing the feedback timely and individually is the principal to improve students' learning. However, it is too difficult for teachers to do that without any support, especially in higher education, where one teacher has to work with many students in short-term interaction. Fortunately, Blended learning - a mixture of face-to-face and online learning with instruction is the best way to improve the shortage of student-instructor face-to-face communication (Vernadakis et al., 2012). It is becoming the trend in higher education over the world.

Because of the Covid-19 outbreak, Vietnam saw an explosive development of online and blended learning courses. That brings exceptional opportunities for the comprehensive fundamental innovation of education, which focuses on formative assessment to nurture learners' competencies at all levels of education. To obtain that purpose, instructors need to create new courses and revise 
existing courses to transition from face-to-face mode to the blended model (Brew, 2008). Not all blended learning courses showed a positive impact on student outcomes (Kember et al., 2010), so course design is very vital. There are five main parts of blended learning courses: Live events, SelfPaced Learning, Collaboration, Assessment, Support Materials (Carman, 2005). Assessment factor is a key factor need to be explored.

To deal with the pandemic, VNU- University of Education has applied blended learning using Moodle as the formal online platform since the school year of 2019 - 2020. The time for online learning has to account for $30 \%$. Moodle and online applications bring many advantages to remote learning, which is compulsory due to social distance. Many of Moodle's functions can increase interaction among students, teachers and helps they give each other feedback immediately such as forums, feedback, chat. With assigment function, students can submit invidually or in group, receive the comments, revise and reassign until they complete good papers . Like the other platform, Moodle can recode and provide students' detailed activities report: how much time they spend studying online and the percentage they complete their missions. The data logs about students' regression are substantial proof to give feedback instantly when they do not get the target. With many advantages, we wonder does the feedback conducted in online platform improve students learning without direct interaction. Therefore, this study's scope confines the picture of online feedback activities in blended learning at VNU - University of Education and finds the answer to how online formative feedback impacts student's motivation and self-directed learning skills during the covid-19 pandemic.

\section{Literature Review}

Blended learning is considered an approach that combines the benefits afforded by face-to-face and online learning components (Rasheed et al., 2020). Blended learning makes the changes of where and when learning happened and what and how the resource can be used to support the learning process (Littlejohn \& Pegler, 2007). Blended learning doesn't mean adding technology to a traditional class; the objective of this approach to education is combining the best features of each platform to promote students' motivation, self-directed learning opportunities with added flexibility (Garnham \& Kaleta, 2002). Devrim Akgündüz \& Orhan Akınoğlu conducted experimental researches on $747^{\text {th }}$ grade students and showed that blended learning had increased academic success and motivation in a meaningful way compared to face-to-face learning(Akgündüz \& Akınoğlu, 2017). Besides some opinions about the effectiveness of blended Learning, Sana et al. showed that studying online causes a significant distraction to both users and fellow students and can be disadvantageous to understanding lecture content (Sana et al., 2013). Kember et al. (2010) researched 509 students taking these 21 blended learning courses about online courses' impact on students' learning outcomes. The results indicated that (1) an online platform used only for presenting information does not seem to improve students' study; (2) blended learning can encourage nurturing communication skills and enhance understanding of content when teachers create interactive learning activities constructive dialogue on a web-based platform. According to those studies, a Blended learning course is practical only when designed with cooperative learning and assessment activities.

Assessment is one of five essential factors in blended learning courses containing Live events, Self-Paced Learning, Collaboration, Assessment, Support Materials (Carman, 2005). Blended learning assessment is activities collecting information about learners' learning process in the blended learning environment, analyzing learners' learning attitudes, performance, and making the value judgment under the learning outcome (Xiufang \& Qingchao, 2008). The assessment is influential in fostering critical thinking, problem-solving, and teamwork (Wu \& Jessop, 2018). Assessment can be divided into 03 types based upon its function; The first is diagnostic assessment aims to identify prior knowledge. Summative assessment provides judgment at the end of the learning process based on criteria and standards (Bacquet, 2020). The last is the formative assessment that provides teachers and students with the information needed to improve learning. Xiufang and Qingchao (2008) pointed out that blended learning assessment needs to use diverse assessment methods, combined 
traditional and web-based assessment with technology support, and emphasizes formative assessment. Formative assessment is one of the most instructional tools for teachers to promote students archievement (Stiggins \& DuFour, 2009) and a key strategy of formative assessment is feedback. (McCallum \& Milner, 2021)

Feedback is the information provided by a representative involving one's performance or understanding. This term can be understood as feedforward, feedthrough, and feedback, which means that feedback lets students know the process-oriented information before or during task implementation (Hummel, 2006). The objective of giving feedback is to identify strengths and weakness, then provide comments for improvement and development so it should be informational and instructional (Hattie \& Timperley, 2007). To enhance instructional function of feedback, Juwah et al. (2004)_proposed 07 principals including (1) Support self-assessment activities (reflection) in learning; (2) Enhance interaction between students and teachers, students and students (peer review); (3) Set and announce standards of good performance. (4) Create a chance to bridge the gap between current and desired performance (5) Provides meaningful information to students about their learning; (6) Promotes positive motivational beliefs and self-esteem; and (7) Provides information to teachers to improve their teaching. Thus, teachers need to design activities that engage students in the feedback process, and adjust the teaching process to help them study better (Noble et al., 2020). Successful feedback needs to be conducted timely, motivational, individual, manageable, directly related to learning outcomes (Hatziapostolou \& Paraskakis, 2010). Based on providers, feedback can be divided into 03 types: teacher feedback, peer feedback and self feedback.

Peer feedback is a process in which students provide an intermediate commend on their teammate performance against the criteria, feedback on strengths, weaknesses, or some tips for improvement (Lowell \& Ashby, 2018). Be different from teacher feedback, and peer judgments may be misleading or incorrect (Gielen et al., 2010). The uncertain correct make students, when receiving peer assessment, have to search for confirmation by checking knowledge, asking the teacher, or performing more self-correction (Gao et al., 2019). When teachers create suitable peer-assessment activities, both students who provide and receive feedback can gain effectiveness from the process by learning from other's mistakes and the internalization of criteria and standards (Topping, 2017). Ertmer, 2010 studied students' perceptions of peer feedback in an online undergraduate course and found that students who joined peer discussion were more confident and easy for sending and responding in online conversations than students who did not receive peer feedback (Ertmer et al., 2010)

Self-assessment is when students grade their work and determine the best way to complete their mission in any situation based on the criteria (Boud, 2013). Self-assessment activities let students know their exact strengths and weakness then revise work accordingly (Andrade \& Du, 2007). Gámiz-Sánchez et al. (2019) conducted experiential research on General Accounting courses, allowing students to undertake online self-assessment in blended-learning environments. The findings highlight participant's interest and utility of activities on the platform; It also pointed a positive correlation between self-evaluation activities and the final grades obtained in the subject.

The influence of online Feedback on student learning

Technology highlights the good advantages of supporting formative feedback in the blended learning model, especially for large higher education classes (Nguyen et al., 2018). Febriani and Abdullah (2018) indicated that in blended learning, among three online feedback tools (automatic, semi-automatic, manual), automatic assessment is the most popular. The percentage of using semiautomatic is lower, and instructors hardly used manual assessment tools. However, using automatic tools required careful preparation to ensure the validity of the feedback. Lim and Wang (2016) proposed o4 levels of apply technology to assessment: (1) Under Consideration: No online learning technologies are used to engage students in the assessment tasks. (2) Emerging/Applying: Online technologies are used; however, there is no connection between the learning and teaching activities and the assessment tasks. (3) Infusing: Online technologies are used; the assessment tasks are supported for the learning and teaching activities. (4) Transforming: Online learning technologies are 
used; The assessment tasks are designed to take up the affordances of online learning technologies and support for learning and teaching activities. Among 04 levels, "Transforming" can be a suitable environment for online feedback and make it effective.

Vaughan (2014) demonstrated that collaborative learning applications (blogs, online quizzes, peer-review tools, portfolio) in a blended approach could be used to design and support feedback activities that enhance student engagement and collaboration. This work can lead to increased student achievement and satisfaction. Enhancing motivation and self-directed learning skills is also listed as the advantages of applying formative feedback in Blended learning environments (Isiguzel, 2014), (Hatziapostolou \& Paraskakis, 2010).

Motivation refers to the combination of an attempt to obtain the objective of learning and desirable attitudes towards the achievement (Alizadeh, 2016). Many researchers pointed that Blended learning has positive effects on students' motivation compared to traditional ones at any level of education (Islam et al., 2018), (Wong et al., 2020). Schober and Keller (2012) noticed o3 blended learning factors impacted students' motivations, including the Features and usability of the LMS in use, facilities at school, and the student's workload. Using LMS or other online systems to give feedback is proved to improve student engagement, motivation, and achievement (Hatziapostolou \& Paraskakis, 2010).

Self-directed learning is an outcome in which individuals take responsibility for their learning (Choi et al., 2014). There are five steps of the Self-directed learning process: (a) identifying learning goals; (b) formulating learning goals; (c) recognizing learning material resources; (d) choosing and implementing appropriate learning strategies and (e) evaluating learning outcomes (Sumuer, 2018). Technology is regarded as one of the best support for developing Self-directed learning. Lin et al. (2008)demonstrated that using online resources helps students diagnose their learning, plan their learning paths and conduct an independent inquiry to deepen their knowledge. Sumuer (2018) researched 153 college students and showed that using Web 2.o tools for learning contributed to Selfdirected learning significantly with technology.

\section{Theoretical Framework}

This study plans to determine the influences of online teacher, peer and self-feedback on motivation and self-directed learning. The proposed research model is shown in Figure 1.

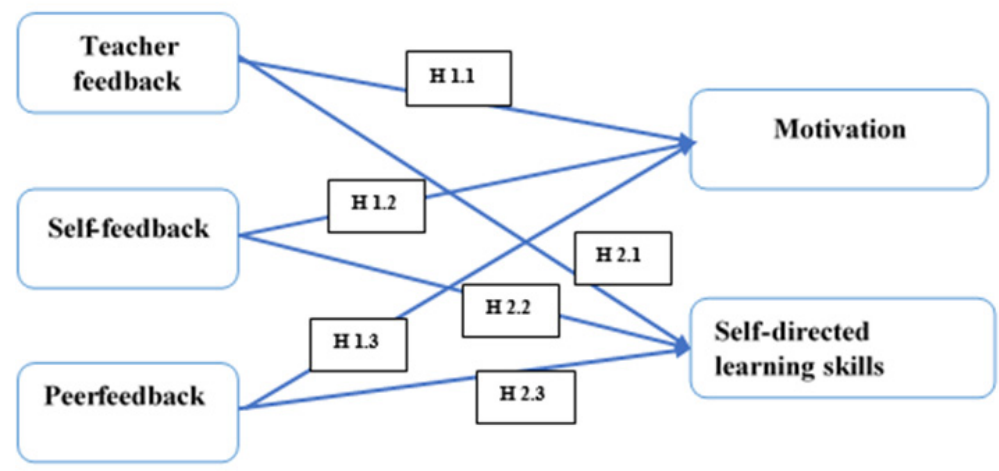

Figure 1: The proposed research's model

In this research, motivation is defined as the eagerness and desire to engage and complete the blended learning courses with high achievement. It was explained by 05 items concerning student's attitude and activities when participating in Blended learning course such as interested in 
participating (Tham (2016); complete the course with high scores (Shen et al. (2013); feel more confident (Kadri and Hamada (2018); Blended learning activities encouraged me to study independently (Kadri and Hamada (2018) and help me achieve my subject's learning goals (Hussein (2015).

The behaviors of Self-directed learning skills in Blended learning environments used in the questionnaire were described as o6 actions: setting a goal and plan for self-study; follow the procedure set out using the online platform; review lessons and completed the missions in Moodle using various software; explore in advance the materials related to the topic from Moodle and other websites; use software to check and keep track of learning progress regularly (Lee et al., 2014).

There are 06 activities related to giving feedback by teacher pertaining: response about the assignment, comment on the academic performance, provides a chance to reassign mission following feedback, perform continuous feedback during the course (before, during, and after), feedback about the strengths and weaknesses to close the gap to the objectives. (Cleveland-Innes and Wilton (2018)

Self-feedback is a procedure that students reflect on their work, following the standards, and learn from their experience to improve the learning process. In this study, Self-feedback contains 04 activities. The first is self-assessing the level of goal achievement after each lesson based on learning outcome on Moodle, the second is writing the reflection on Moodle to check the process, next is giving a mark to own work on the online system, and the last is self-assessing academic tasks according to the criteria.

Peer feedback is the instructor-guide activity in which students observe and assess other members' performance based on the criteria. Here some statements used in research to ask about peer assessment: (1) I make comments on my classmates' performance in Moodle system (forum, workshop, etc.), (2) I make comments on the performance of my team members in Moodle system, and directly (3) I give points on my team members' performance and contribution to the mission (4) I was encouraged to observe my friend's academic tasks.

\section{Methods and Procedure}

Survey research was applied to gather information from students who have completed at least seven blended learning courses in Covid-19 crisis times. They are asked to choose one of the courses to describe some learning and assessment activities' frequency. $100 \%$ of classes at VNU-University of Education have to use Moodle platform with some requirements: (1) Before entering the course, an introduction video and subject curriculum are uploaded in Moodle to provide students information about the course's learning outcome, the main content, assessment mission, and the way to scoring, (2) During the period, some assessment functions (assignment, forum, workshop, quizzes, reflection) are used to measure and discuss students' learning process by the teacher, students' teammates, and themselves, (3) the score, data log, feedback need to be provided for students. However, the faculties can freely use the assessment methods, tools following the curriculum.

\subsection{Instrument}

There are four parts to the questionnaire. The first session (A) gathers information about participants like gender, major. The following two features include items that describe the snapshot of the blended learning state in VNU- University of Education (B) and the frequency of formative feedback activities (C) using Likert 4 points from "never" to "always". Part $C$ has o3 components: Teacher feedback, peer feedback, and self-feedback. The last is about students motivation and self-directed learning skills) using 4 points scale from "Strongly disagree" to "Strongly Agree." The items of that session have adjusted after the pilot test. 


\subsection{Questionnaire Analysis}

Partial least squares structural equation modeling (PLS-SEM) is used to confirm the Reliability and Validity of the questionnaire.

First, Cronbach's Alpha and composition reliability (CR) were analyzed. The results for the o5 groups are above 0.7 , which showed the excellent consistencies of scale.

Table 1: Measurement Model Results

\begin{tabular}{lccc}
\hline & Cronbach's Alpha & Composite Reliability & (AVE) \\
\hline Motivation & 0.882 & 0.914 & 0.680 \\
\hline Self directed learning skills & 0.880 & 0.909 & 0.626 \\
\hline Self-feedback & 0.751 & 0.857 & 0.667 \\
\hline Teacher feedback & 0.919 & 0.936 & 0.711 \\
\hline peer feedback & 0.910 & 0.938 & 0.793 \\
\hline
\end{tabular}

Table 2: Fornell-Larcker Criterion Results

\begin{tabular}{lccccc}
\hline & Motivation & $\begin{array}{c}\text { Self directed } \\
\text { learning skills }\end{array}$ & Self-feedback & Teacher feedback & peer feedback \\
\hline Motivation & 0.824 & & & & \\
\hline Self directed learning skills & 0.534 & 0.791 & & & \\
\hline Self-feedback & 0.352 & 0.351 & 0.817 & & \\
\hline Teacher feedback & 0.483 & 0.420 & 0.451 & 0.843 & 0.890 \\
\hline peer feedback & 0.411 & 0.393 & 0.566 & 0.560 &
\end{tabular}

Table 3: Heterotrait-monotrait ratio of correlations.

\begin{tabular}{lccccc}
\hline & Motivation & $\begin{array}{c}\text { Self-directed } \\
\text { learning skills }\end{array}$ & $\begin{array}{c}\text { Self- } \\
\text { feedback }\end{array}$ & $\begin{array}{c}\text { Teacher } \\
\text { feedback }\end{array}$ & $\begin{array}{c}\text { peer } \\
\text { feedback }\end{array}$ \\
\hline Motivation & & & & & \\
\hline $\begin{array}{l}\text { Self-directed learning } \\
\text { skills }\end{array}$ & 0.606 & & & \\
\hline Self-feedback & 0.428 & 0.430 & & \\
\hline Teacher feedback & 0.535 & 0.464 & 0.537 & \\
\hline peer feedback & 0.457 & 0.440 & 0.685 & 0.609 \\
\hline
\end{tabular}

Secondly, validity (including convergent, discriminant validity) verifies whether the scale truly measures what it needs to do. All indicators in the study are significant and have more than 0.5 , and AVE values are higher than 0.5 . Therefore the convergent validity is acceptable. In terms of discriminant validity, Fornell-Larcker Criterion is used. Table 2 showed that the AVE square root (SQRTAVE) is greater than any Inter-Construct Correlations, so the discriminant validity is confirmed. In addition, Heterotrait-monotrait analysis results in table 3 pointed out that less all correlations are less than 0.85 , indicating good discriminant validity. According to Threshold, all factors of the model have excellent reliability and validity.

\section{Procedure}

The survey was sent to 645 students in the middle of the $2^{\text {nd }}$ semester (2019 - 2020 school year), so After getting and cleaning data, 451 cases were kept for analysis. Table 4. shows the demographic profile of survey participants. $89.2 \%$ of participants are female and all of them have joined at least 7 blended learning courses. 
Table 4: Demographic information

\begin{tabular}{lc}
\hline & Percent of Total (\%) \\
\hline Gender & 10,2 \\
Male & 89,8 \\
Female & \\
A number of blended courses have joined & 69,4 \\
$\leq 7$ & 14,5 \\
$7-14$ & 16.1 \\
$\geq 14$ & \\
Major & 34,9 \\
Pedagogy of Natural Science & 45,1 \\
Pedagogy of Social Science & 20 \\
Educational Sciences &
\end{tabular}

\section{Results}

6.1 The impacts of online feedback activities on student's motivation and self-directed learning skills

SEM analysis was employed to confirm the proposed research model. Three kinds of feedback are predictor variables, and Motivation and Self-directed learning skills are the outcome variables for the analysis. The model's fit indicators showed an excellent fit and confirmed the model's structure with SRMR $=0.07$, less than 0.8 ; NFI is greater than 0.88 and RMS theta $=0.123$.

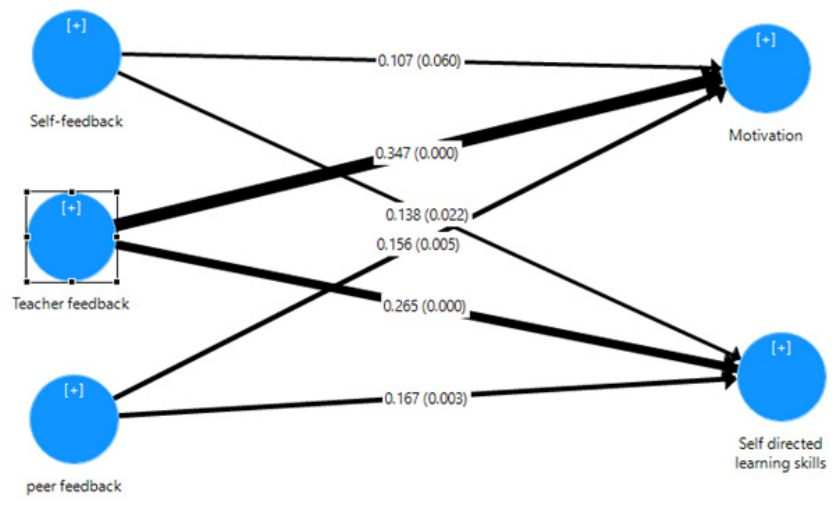

Figure 2: SEM model

The estimated model is given in table 5 .

Table 5: Path coefficients

\begin{tabular}{llccc}
\hline & & Original Sample $($ O) & P Values & Remark \\
\hline H1.2 & Self-feedback $->$ Motivation & 0.107 & 0.060 & \\
\hline H2.2 & Self-feedback $->$ Self directed learning skills & 0.138 & 0.022 & Support \\
\hline H1.1 & Teacher feedback $->$ Motivation & 0.347 & 0.000 & Support \\
\hline H2.1 & Teacher feedback $->$ Self directed learning skills & 0.265 & 0.000 & Support \\
\hline H1.3 & peer feedback $->$ Motivation & 0.156 & 0.005 & Support \\
\hline H2.3 & peer feedback $->$ Self directed learning skills & 0.167 & 0.003 & Support \\
\hline
\end{tabular}


The model fit with the data is accepted as the p-values for the average path coefficient were less than o.o5. Teacher feedback has the highest positive significant effects on student motivation and selfdirected learning skills among the three kinds of feedback. Both path coefficients are over 0,265 (p < 0.05). The effects of peer feedback on motivation and self-directed learning skills are lower, at 0.156 and 0.167 , respectively. In comparison, self-feedback is also a significant positive factor associated with self-directed learning skills $(0.138, \mathrm{p}<0.05)$, it has no impact on student motivation ( $\mathrm{p}>0.05)$. That SEM results support hypotheses 1 and 2, except for the relationship between online selffeedback and motivation.

\section{Discussion and Conclusion}

Several studies have demonstrated the effectiveness of formative assessment with technology to support students' outcomes (Islam et al., 2018; Schober \& Keller, 2012, K. Lee et al., 2014; Wong et al., 2020). Some others implied that efficiency depends on how instructors use technology to design and conduct the assessment process. (Sana et al., 2013, Kember, 2010). Thus, this research aims to study the state of formative assessment feedback activities on Moodle at VNU-University of Education and their influence on students' motivation and self-directed learning skills.

Firstly, let start with the snapshot of the state about online formative assessment VNUUniversity of Education. The results showed that instructors have taken advantage of Moodle and digital applications to design online activities: forums, online assignments, etc. Most instructors used Moodle to assign missions (98.5\%) and feedback for students to prepare before and after live events $(99,2 \%) .20 \%$ of learners have to do the quick test with the feedback every lesson. Regarding online feedback, teacher feedback is the most popular choice of instructors, with mean scores of each item from 3,17 $(\mathrm{SD}=0.623)$ to 3,22 $(\mathrm{SD}=0,636)$. Approximately $10 \%$ of students disagree with statements about teacher feedback. The frequencies of using peer feedback are lower, at $2.8(\mathrm{SD}=0.65)$. In contrast, instructors spent less time on online self-feedback (mean $=2,80, \mathrm{SD}=0,65$ ). Among the three self-feedback activities, "Write the reflection on Moodle" is used more than others (mean = $2,96, \mathrm{SD}=0,779$ ). Moodle platform can enhance the quality of assessment and feedback provided by instructors and a fantastic opportunity to share good practices across the college (Jackson, 2017). Therefore, VNU-UEd saw a significant shift from using the traditional paper test to numerous digital tools. Assessment activities can be assessed as transforming levels following the blended assessing model framework (Lim \& Wang, 2016). The assessment tasks are designed to make use of online learning technologies and support for learning and teaching activities.

Secondly, it can be seen from the survey results, the faculties at VNU- University of Education perform well feedback activities (90\% of students said that their lectures make continuous feedback during the course, and the percentage for timely feedback is more than $85 \%$ ). The responses also help students know their strengths and weaknesses to improve their performance ( $>80 \%$ of students agree with those statements). That confirms the quality of feedback (Hatziapostolou \& Paraskakis, 2010). Therefore, online teacher feedback shows a significant impaction on both students' motivation and self-directed learning skills. The result for peer feedback is similar, but the path coefficient is lower. Another interesting finding is that online self-feedback have no impact on student' motivation. Those results indicated the frequency and procedure of assessment activities are critical factors of a successful blended course. That also gives an implication for designing assessment activities on Moodle. The lectures should publish the success criteria for each mission and guild students on how to assess their performance. Furthermore, the writing reflection is one of the most influential factors of self-feedback activities (Estimate $=0,8$ ) and significantly enhances students' self-directed learning in online platforms (Jenson, 2011). Thus, making an electronic portfolio containing all students' writing reflections on Moodle should be considered to help both lectures and students follow the study process.

Regarding future research lines, the research team would like to design Moodle formative assessment toolkits to help instructors and students use them effectively for feedback purposes. 
Those toolkits are expected to be suitable for not only higher education systems but all other education levels also.

\section{Acknowledgements}

This study is supported by the Vietnam National University, Hanoi, under project number QG.20.46

\section{Reference}

Akgündüz, D., \& Akınoğlu, O. (2017). The Impact of Blended Learning and Social Media-Supported Learning on the Academic Success and Motivation of the Students in Science Education. Education \& Science/Egitim ve Bilim, 42(191).

Alizadeh, M. (2016). The impact of motivation on English language learning. International Journal of Research in English Education, 1(1), 11-15.

Andrade, H., \& Du, Y. (2007). Student responses to criteria-referenced self-assessment. Assessment E Evaluation in Higher Education, 32(2), 159-181.

Bacquet, J. N. (2020). Implications of Summative and Formative Assessment in Japan-A Review of the Current Literature. International Journal of Education and Literacy Studies, 8(2), 28-35.

Boud, D. (2013). Enhancing learning through self-assessment. Routledge.

Brew, L. S. (2008). The role of student feedback in evaluating and revising a blended learning course. The Internet and Higher Education, 11(2), 98-105.

Carman, J. M. (2005). Blended learning design: Five key ingredients. Agilant Learning, 1-11.

Cleveland-Innes, M., \& Wilton, D. (2018). Guide to blended learning. In: Commonwealth of Learning (COL).

Choi, E., Lindquist, R., \& Song, Y. (2014). Effects of problem-based learning vs. traditional lecture on Korean nursing students' critical thinking, problem-solving, and self-directed learning. Nurse education today, $34(1)$, 52-56.

Ertmer, P. A., Richardson, J. C., Lehman, J. D., Newby, T. J., Cheng, X., Mong, C., \& Sadaf, A. (2010). Peer feedback in a large undergraduate blended course: Perceptions of value and learning. Journal of Educational Computing Research, 43(1), 67-88.

Febriani, I., \& Abdullah, M. I. (2018). A systematic review of formative assessment tools in the blended learning environment. Int. J. Eng. Technol, 7, 33-39.

Gámiz-Sánchez, V., Gutiérrez-Santiuste, E., \& Hinojosa-Pareja, E. (2019). Influence of Professors on Student Satisfaction with e-Portfolio use. Journal of Educational Computing Research, 57(3), 646-669.

Gao, Y., Schunn, C. D. D., \& Yu, Q. (2019). The alignment of written peer feedback with draft problems and its impact on revision in peer assessment. Assessment \& Evaluation in Higher Education, 44(2), 294-308.

Garnham, C., \& Kaleta, R. (2002). Introduction to hybrid courses. Teaching with technology today, 8(6), 5.

Garrison, C., \& Ehringhaus, M. (2007). Formative and summative assessments in the classroom. In.

Gielen, S., Peeters, E., Dochy, F., Onghena, P., \& Struyven, K. (2010). Improving the effectiveness of peer feedback for learning. Learning and instruction, 20(4), 304-315.

Hattie, J., \& Timperley, H. (2007). The power of feedback. Review of Educational Research, 77(1), 81-112.

Hatziapostolou, T., \& Paraskakis, I. (2010). Enhancing the impact of formative feedback on student learning through an online feedback system. Electronic Journal of E-learning, 8(2), 111-122.

Hummel, H. G. K. (2006). Feedback Model to Support Designers of Blended Learning Courses. The International Review of Research in Open and Distributed Learning, 7(3). https://doi.org/10.19173/irrodl.v7i3.379

Hussein, B. A. (2015). A blended learning approach to teaching project management: A model for active participation and involvement: Insights from Norway. Education Sciences, 5(2), 104-125. https://doi.org/ 10.3390/educsci5020104

Isiguzel, B. (2014). The blended learning environment on the foreign language learning process: A balance for motivation and achievement. Turkish Online Journal of Distance Education, 15(3), 108-121.

Islam, S., Baharun, H., Muali, C., Ghufron, M. I., el Iq Bali, M., Wijaya, M., \& Marzuki, I. (2018). To Boost Students' Motivation and Achievement through Blended Learning. Journal of Physics: Conference Series,

Jackson, E. A. (2017). Impact of MOODLE platform on the pedagogy of students and staff: Cross-curricular comparison. Education and Information Technologies, 22(1), 177-193.

Jenson, J. D. (2011). Promoting Self-Regulation and Critical Reflection through Writing Students' Use of Electronic Portfolio. International Journal of ePortfolio, 1(1), 49-6o. 
Juwah, C., Macfarlane-Dick, D., Matthew, B., Nicol, D., Ross, D., \& Smith, B. (2004). Enhancing student learning through effective formative feedback. The Higher Education Academy, 140, 1-40.

Kadri, S., \& Hamada, H. (2018). The effect of blended learning on EFL learners' motivation and academic writing

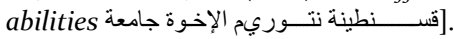

Kember, D., McNaught, C., Chong, F. C., Lam, P., \& Cheng, K.-F. (2010). Understanding the ways in which design features of educational websites impact upon student learning outcomes in blended learning environments. Computers E Education, 55(3), 1183-1192.

Lee, K., Tsai, P. S., Chai, C. S., \& Koh, J. H. L. (2014). Students' perceptions of self-directed learning and collaborative learning with and without technology. Journal of Computer Assisted Learning, 30(5), 425-437.

Lim, C. P., \& Wang, L. (2016). Blended learning for quality higher education: selected case studies on implementation from Asia-Pacific. UNESCO Bangkok Office.

Lin, Y.-M., Lin, G.-Y., \& Laffey, J. M. (2008). Building a social and motivational framework for understanding satisfaction in online learning. Journal of Educational Computing Research, 38(1), 1-27.

Littlejohn, A., \& Pegler, C. (2007). Preparing for blended e-learning. Routledge.

Lowell, V. L., \& Ashby, I. V. (2018). Supporting the development of collaboration and feedback skills in instructional designers. Journal of Computing in Higher Education, 30(1), 72-92.

McCallum, S., \& Milner, M. M. (2021). The effectiveness of formative assessment: Student views and staff reflections. Assessment \& Evaluation in Higher Education, 46(1), 1-16.

Noble, C., Billett, S., Armit, L., Collier, L., Hilder, J., Sly, C., \& Molloy, E. (2020). “It's yours to take”: generating learner feedback literacy in the workplace. Advances in Health Sciences Education, 25(1), 55-74.

Nguyen, Q., Thorne, S., \& Rienties, B. (2018). How do students engage with computer-based assessments: impact of study breaks on intertemporal engagement and pass rates. Behaviormetrika, 45(2), 597-614.

Rasheed, R. A., Kamsin, A., \& Abdullah, N. A. (2020). Challenges in the online component of blended learning: A systematic review. Computers \& Education, 144, 103701.

Sana, F., Weston, T., \& Cepeda, N. J. (2013). Laptop multitasking hinders classroom learning for both users and nearby peers. Computers \& Education, 62, 24-31.

Schober, A., \& Keller, L. (2012). Impact factors for learner motivation in Blended Learning environments. International Journal of Emerging Technologies in Learning (iJET), 7(2012).

Shen, D., Cho, M.-H., Tsai, C.-L., \& Marra, R. (2013). Unpacking online learning experiences: Online learning selfefficacy and learning satisfaction. The Internet and Higher Education, 19, 10-17. https://doi.org/10.1016/ j.iheduc.2013.04.001

Stiggins, R., \& DuFour, R. (2009). Maximizing the power of formative assessments. Phi Delta Kappan, 9o(9), 640644 .

Sumuer, E. (2018). Factors related to college students' self-directed learning with technology. Australasian Journal of Educational Technology, 34(4).

Topping, K. (2017). Peer assessment: Learning by judging and discussing the work of other learners. Interdisciplinary Education and Psychology, 1(1), 1-17.

Tham, R. K. O. (2016). Student motivation to engage in blended learning: a Singapore case study University of Newcastle].

Vaughan, N. (2014). Student engagement and blended learning: Making the assessment connection. Education Sciences, 4(4), 247-264.

Vernadakis, N., Giannousi, M., Derri, V., Michalopoulos, M., \& Kioumourtzoglou, E. (2012). The impact of blended and traditional instruction in students' performance. Procedia Technology, 1, 439-443.

Wong, K.-T., Hwang, G.-J., Choo Goh, P. S., \& Mohd Arrif, S. K. (2020). Effects of blended learning pedagogical practices on students' motivation and autonomy for the teaching of short stories in upper secondary English. Interactive Learning Environments, 28(4), 512-525.

Wu, Q., \& Jessop, T. (2018). Formative assessment: missing in action in both research-intensive and teaching focused universities? Assessment E Evaluation in Higher Education, 43(7), 1019-1031.

Xiufang, M., \& Qingchao, K. (2008). Assessment in blended learning: A framework for design and implementation. 2008 International Conference on Computer Science and Software Engineering, 